\title{
Banki syndrome
}

INSERM

\section{Source}

INSERM. (1999). Orphanet: an online rare disease and orphan drug data base. Banki syndrome. ORPHA:1228

Banki syndrome is a synostosis syndrome, reported in a single Hungarian family in which members of 3 generations showed lunotriquetral synostosis, clinodactyly,

clinometacarpy, brachymetacarpy and leptometacarpy (thin diaphysis). It appeared to be a unique dominant mutation. There have been no further descriptions in the literature since 1965. 